\title{
Elementary Kinetic Numerical Simulation of Ni/YSZ SOFC Anode Performance Considering Sulfur Poisoning
}

\author{
Matthias Riegraf, ${ }^{\text {a,z }}$ Günter Schiller, ${ }^{\text {a }}$ Rémi Costa, ${ }^{a}$ K. Andreas Friedrich,,${ }^{\mathrm{a}, *}$ Arnulf Latz, ${ }^{\text {a,b,* }}$ \\ and Vitaliy Yurkiv ${ }^{\mathrm{a}}$
}

${ }^{a}$ German Aerospace Centre (DLR), Institute of Engineering Thermodynamics, 70569 Stuttgart, Germany

${ }^{b}$ Helmholtz Institute Ulm (HIU), Electrochemical Energy Storage, 89081 Ulm, Germany

\begin{abstract}
An elementary kinetic model is developed and applied to explore the influence of sulfur poisoning on the behavior of solid oxide fuel cell (SOFC) anodes. A detailed multi-step reaction mechanism of sulfur formation and oxidation at Ni/YSZ anodes together with channel gas-flow, porous-media transport and elementary charge-transfer chemistry is established for SOFCs operating on $\mathrm{H}_{2} / \mathrm{H}_{2} \mathrm{O}$ mixtures with trace amounts of hydrogen sulfide $\left(\mathrm{H}_{2} \mathrm{~S}\right)$. A thermodynamic and kinetic data set is compiled from various literature sources. The derived chemical model, validated against sulfur chemisorption isobars taken from literature, is used to analyze performance drops of SOFCs working under typical fuel cell operating conditions. Electrochemical results show that at relatively low $\mathrm{H}_{2} \mathrm{~S}$ concentrations SOFC button-cell performance can be interpreted using chemical sulfur formation. However, when the concentration is sufficiently high, the inclusion of second stage degradation and triple-phase boundary reconstruction is necessary to describe the performance decrease. Additionally, it is shown that the sulfur surface coverage increases with increasing current density. In order to shed more light on advanced fundamental understanding of cell poisoning, sensitive analyses toward total anode resistance and sulfur coverage for different operating conditions were performed.

(C) 2015 The Electrochemical Society. [DOI: 10.1149/2.0471501jes] All rights reserved.
\end{abstract}

Manuscript submitted September 9, 2014; revised manuscript received October 29, 2014. Published November 13, 2014.

Solid oxide fuel cells (SOFCs) are a promising technology for supplying electrical energy for future demands. Due to many advantages such as high efficiency, low emissions, low noise, reliability, and fuel flexibility, SOFCs are expected to take over a major role in future stationary energy conversion technologies. ${ }^{1}$ It has been demonstrated that SOFCs are a well-suited electrical power source for a variety of applications, ranging from mobile technology (e.g. auxiliary power units) to stationary power plants. ${ }^{1}$

Due to high operating temperatures, SOFCs can easily work with natural gas and a variety of hydrocarbons (e.g. methane, propane, dodecane). ${ }^{2}$ An alternative and very promising source of hydrocarbons is biomass gasification. The obtained biogas (mainly methane and carbon oxides) is a renewable fuel source which can contribute to the reduction of fossil fuel usage and emission of greenhouse gases. However, depending on the content of biomass, the resulting biogas may contain some undesirable species that upon contact with the SOFC anode could lead to electrode degradation. One of such compounds is hydrogen sulfide which via catalytic dissociation at the anode surface is converted into atomic hydrogen and sulfur. Consequently, SOFC failure in a relatively short period of time can happen depending upon the sulfur amount in the supply gas.

Although being widely investigated, the microscopic details of the elementary chemical reaction mechanism of SOFC sulfur poisoning occurring at the Ni/YSZ anode are not fully understood. ${ }^{3}$ Yet, the knowledge of elementary kinetics of SOFC electrode degradation is important because the understanding at the fundamental level yields better predictive capability, which allows optimal design and operation of new fuel cell systems. Thus, an important objective of this paper is to describe SOFC anode poisoning processes considering the elementary reaction mechanism of sulfur formation/oxidation coupled to multicomponent flow and charge-transfer chemistry.

\section{State of Knowledge: Prior Literature Study}

Over the last few decades, many studies have experimentally investigated sulfur poisoning of $\mathrm{Ni} / \mathrm{YSZ}$ anodes ${ }^{4-10}$ (and references therein). In these studies, the influence of a variety of parameters (as e.g. temperature, current density, gas phase composition, operation mode, etc.) on the extent of sulfur poisoning was systematically examined. However, there is significant discrepancy between these studies concerning the interpretation of the results. For that reason relevant prior literature is shortly reviewed in the following.

\footnotetext{
*Electrochemical Society Active Member.
}

${ }^{\mathrm{z} E-m a i l: ~ M a t t h i a s . R i e g r a f @ d l r . d e ~}$
Based upon results published previously a few general trends can be deduced. In all cases, a rapid initial power output drop occurs already for concentrations of $\mathrm{H}_{2} \mathrm{~S}$ as low as $0.05 \mathrm{ppm}^{7}$ This power output drop is associated with a large increase in total anode resistance and is assumed to be the result of the active surface site blockage by adsorbed sulfur. When the supply of $\mathrm{H}_{2} \mathrm{~S}$ is cut-off, in most cases performance recovers completely to its initial value. However, this recovery process could have a different rate than the rapid poisoning of the anode depending upon experimental conditions. ${ }^{5}$ For long-term cell operation with $\mathrm{H}_{2} \mathrm{~S}$ impurities, a slow, mostly irreversible, second stage degradation has been reported in many studies. ${ }^{4,5}$ However, the mechanism for this long-term degradation is unclear and yet to be identified. Recently, surface reconstruction and increased Ni sintering rates due to the dissolution of sulfur atoms into the Ni bulk phase have been suggested..$^{5,11}$

The initial performance drop was found to decrease with increasing temperature which can be explained by a decrease of sulfur equilibrium coverage. ${ }^{5,7}$ Since a higher $\mathrm{H}_{2} \mathrm{~S}$ concentration also leads to higher equilibrium sulfur coverage, an increasing power output drop for increasing $\mathrm{H}_{2} \mathrm{~S}$ concentrations was observed. However, this increase levels off and reaches a constant value once saturation coverage is approached $^{5,7}$ which was experimentally determined to be $\theta\left(\mathrm{S}_{\mathrm{Ni}}\right)=$ $0.5 \mathrm{ML}$ (monolayer). ${ }^{12}$ Regarding the influence of current density on sulfur poisoning, different behaviors have been observed depending on the operation mode. In the case of galvanostatic mode, the relative power output drop has been shown to increase with increasing current density. For potentiostatic mode, the opposite situation has been observed, that is, the power output drop decreases with current density. This apparent contradiction was resolved by Cheng et al. using equivalent circuit analysis. ${ }^{6}$ In order to avoid confusion, the authors suggested rather to use the increase in total anode resistance to describe the degree of sulfur poisoning, which decreases with current density in both potentiostatic and galvanostatic mode. This trend was speculated to originate from the oxidation of sulfur at the triple phase boundary (TPB) and its subsequent removal, as represented by the global reaction in Eq. $1^{5,6,13,14}$

$$
\mathrm{S}_{\mathrm{Ni}}+2 \mathrm{O}_{\mathrm{YSZ}}^{2-} \rightleftharpoons \mathrm{SO}_{2, \mathrm{~g}}+\square_{\mathrm{Ni}}+2 \square_{\mathrm{YSZ}}+4 \mathrm{e}^{-}
$$

However, recently it has been shown that in the Tafel region the relative increase of the total anode resistance due to sulfur poisoning always depends inversely on current density. Thus, the observed trend does not necessarily have to be the result of reduced sulfur coverage. ${ }^{15}$ These contradicting hypotheses illustrate that the mechanistic details underlying sulfur poisoning are still unclear. 
Most theoretical analyses of sulfur poisoning of Ni-based anodes have been performed with density functional theory (DFT). These studies can be structured into two groups: first, the investigation of adsorption of $\mathrm{H}_{2} \mathrm{~S}$ on $\mathrm{Ni}$ surfaces and the subsequent formation of atomic sulfur, ${ }^{16,17}$ and second, the removal of atomic sulfur by oxygen. ${ }^{18,19}$ Recently, a unique approach to investigate sulfur poisoning of Ni surfaces has been accomplished by Monder et al. ${ }^{20}$ They have used DFT calculations to determine the coverage dependency of the thermodynamic properties of nickel-adsorbed sulfur concluding that the sulfur enthalpy changes significantly depending on its coverage.

Only few attempts in literature were made to investigate the relation between the enthalpy of nickel-adsorbed sulfur and its coverage on Ni/YSZ SOFC anodes. ${ }^{3,21,22}$ Alstrup et al. ${ }^{23}$ have proposed the Temkin-like isotherm in order to predict the fractional coverage of sulfur on Ni surfaces described by Eq. 2

$$
\frac{p_{\mathrm{H}_{2} \mathrm{~S}}}{p_{\mathrm{H}_{2}}}=\exp \left(\Delta h_{0}^{0}\left(1-a \theta_{\mathrm{S}}\right) / R T-\Delta s^{0} / R\right),
$$

where $\Delta h_{0}^{0}=289 \mathrm{~kJ} \cdot \mathrm{mol}^{-1}, \Delta s^{0}=19 \mathrm{~J} \cdot \mathrm{mol}^{-1} \cdot \mathrm{K}^{-1}$ and $a=0.69$. This isotherm was also used by Hansen to describe the relation between observed relative power output drops and the calculated sulfur coverage. As a result, a linear relationship between coverage and enthalpy of sulfur was obtained. ${ }^{22}$ Cayan et al. have employed a semi-empirical approach to create a comprehensive model to predict degradation rates and cell performance losses in Ni-YSZ anodes due to exposure to $\mathrm{H}_{2} \mathrm{~S}$ and other contaminants. ${ }^{21}$ This model includes gas phase and surface diffusion within the anode and the adsorption reactions on the surface of electrodes coupled to chemical poisoning reactions. In contrast to the present modeling approach, where all (electro-)chemical processes are expressed as elementary reactions, their model requires the indirect calibration of physico-chemical parameters to predict degradation rates.

To our knowledge, Prasad et al. are first to publish an elementary kinetic model developing a rate expression for the sulfur coverage during the poisoning process via formation of surface-adsorbed atomic sulfur. ${ }^{3}$ They have coupled a kinetic model to a one-dimensional $\mathrm{Ni} / Y S Z$ based button cell model to simulate the impedance response and the performance drop of the cell operating with different $\mathrm{H}_{2} \mathrm{~S}$ concentrations. Based upon their modeling results and a thorough comparison with different experimental data, they have concluded that high operation temperature and low $\mathrm{H}_{2} \mathrm{~S}$ concentration in the feed gas can mitigate sulfur poisoning.

Despite the extensive effort to theoretically understand sulfur poisoning, alternatively different experimental procedures could be adopted to avoid it. One widely employed approach is the use of a desulfurization unit in order to minimize the sulfur content in the fuel inlet gas. However, this leads to a drastic increase in complexity, cost, and maintenance burden of the system. Currently, in order to use less and lower cost material, it is attempted to lower the SOFC operation temperature into the so-called intermediate temperature (IT) range at about $700 \mathrm{~K} .{ }^{24}$ However, it was found that at these conditions sulfur poisoning of Ni-based anodes is even more severe. ${ }^{5,7}$ Therefore, further comprehensive theoretical investigation is important to shed more light on the actual origins of surface-adsorbed sulfur and limitations of SOFC anode systems operating with hydrogen sulfide impurities.

In the present paper, an elementary kinetic model is developed to describe SOFC Ni/YSZ anode degradation due to sulfur poisoning in systems operating with $\mathrm{H}_{2} / \mathrm{H}_{2} \mathrm{O} / \mathrm{H}_{2} \mathrm{~S}$ mixtures. A consistent thermodynamic and kinetic data set is derived. The developed model is validated against different experimental data from literature. The model couples gas transport in the supply chamber of a button cell, porous-media transport, and an elementary kinetic description of heterogeneous chemical and electrochemical reactions.

\section{Modeling and Simulation Methodology}

Approach.- In this section, the model of a Ni/YSZ-based SOFC button cell is briefly described. Figure 1 illustrates the cell configuration which is the geometry used in our model. Because the residence time of the fluid flow in the active section of the button cell is short and the surface diameter being much larger than the gap distance, a one-dimensional physical model is sufficient to describe SOFC performance. The model is based upon our previously published modeling framework ${ }^{25-27}$ and consists of the following features:

- All chemical processes (thermal and electrochemical) are formulated as elementary reactions. The rate of all processes is described by mass-action kinetics under the mean-field assumption. ${ }^{28}$

- Composite electrodes are represented in a continuum approach using effective transport coefficients for mass and charge. The gas transport within the porous phase is described by Stefan-Maxwell and Darcy viscous flow. The model is one-dimensional through the thickness of electrodes and electrolyte.

- The gas supply volume in this button cell design is represented by an isothermal finite-gap stagnation point flow model using a onedimensional representation of Navier-Stokes equations. ${ }^{29}$

Simulation methodology.- Simulations were carried out using the in-house software package DENIS. All model equations used in the present modeling and simulation are thoroughly described elsewhere. ${ }^{25,26}$ Spatial derivatives are discretized using the finitevolume method and the resulting differential-algebraic equation system is integrated by means of the semi-implicit extrapolation solver LIMEX. ${ }^{30}$ In order to characterize SOFC performance during

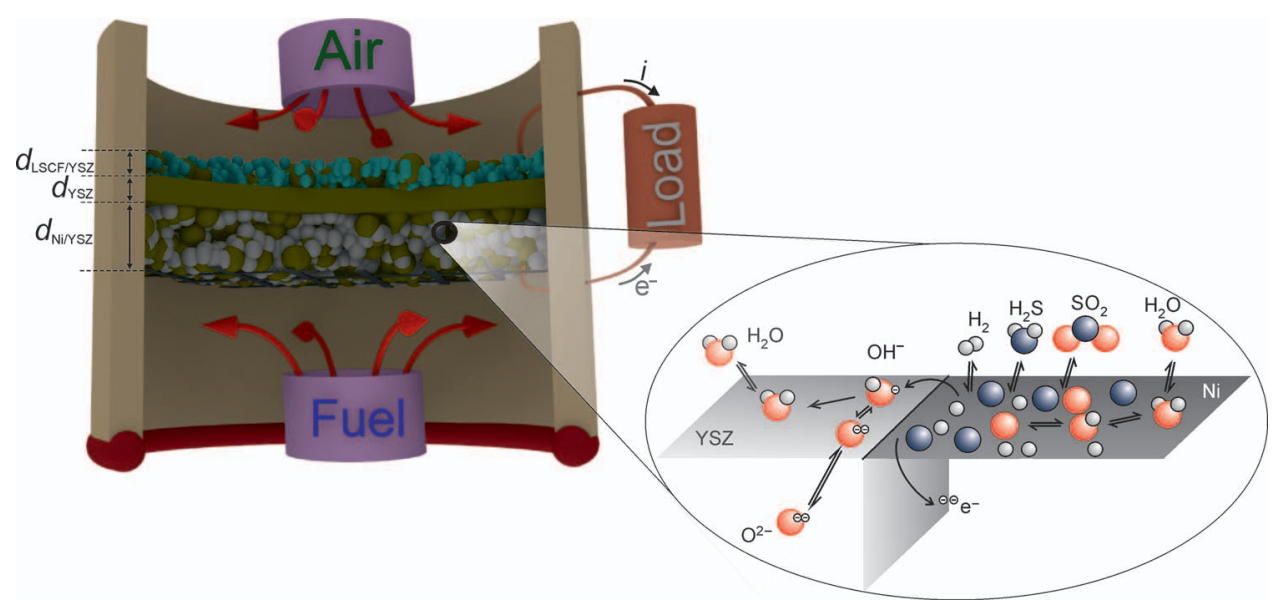

Figure 1. Schematic illustration of the SOFC button cell configuration used in the present study. See text and Table I for details. Note that all structural details and scaling are exaggerated merely for illustration purposes 


\begin{tabular}{|c|c|c|}
\hline Parameter & Value & Reference \\
\hline \multicolumn{3}{|l|}{$\mathrm{Ni} / Y S Z$ Anode } \\
\hline Anode porosity, $\varepsilon$ & 0.35 & Estimated \\
\hline $\begin{array}{l}\text { Anode/gas surface } \\
\text { specific area }\end{array}$ & $2.0 \cdot 10^{6} \mathrm{~m}^{2} \cdot \mathrm{m}^{-3}$ & Estimated \\
\hline Anode tortuosity, $\tau$ & 2 & Estimated \\
\hline Ni particle radius & $0.5 \mu \mathrm{m}$ & Assumed \\
\hline Anode pore size, $d_{\mathrm{P}, \mathrm{A}}$ & $1 \mu \mathrm{m}$ & Assumed \\
\hline Surface site density, $\Gamma_{\mathrm{Ni}}$ & $6.1 \cdot 10^{-5} \mathrm{~mol} \cdot \mathrm{m}^{-2}$ & 32,35 \\
\hline $\begin{array}{l}\text { Interfacial DL } \\
\text { capacitance, } C_{\mathrm{DL}}^{\mathrm{In}} \\
\text { YSZ Electrolyte }\end{array}$ & $1 \mathrm{~F} \cdot \mathrm{m}^{-2}$ & Fit \\
\hline $\begin{array}{l}\text { Ionic conductivity of } \\
\text { bulk YSZ, }\end{array}$ & $T /\left(1.4 \cdot 10^{7} \mathrm{~K}\right) \cdot \mathrm{e}^{\left(90000 \mathrm{~J} / k_{\mathrm{B}} T\right)} \mathrm{S} / \mathrm{m}$ & 32,33 \\
\hline $\begin{array}{l}\text { Surface site density, } \\
\Gamma_{\mathrm{YSZ}}\end{array}$ & $1.1 \cdot 10^{-5} \mathrm{~mol} \cdot \mathrm{m}^{-2}$ & 32,33 \\
\hline Bulk density, $\rho_{Y S Z}$ & $6800 \mathrm{~kg} \cdot \mathrm{m}^{-3}$ & 32,33 \\
\hline $\begin{array}{l}\text { Bulk vacancy/oxygen } \\
\text { fraction }\end{array}$ & $0.0401 / 0.9599$ & 32,33 \\
\hline $\begin{array}{l}\text { LSCF Cathode } \\
\text { LSCF/gas surface } \\
\text { specific } \\
\text { area, } A_{\mathrm{LSCF} / \mathrm{Gas}}^{V}\end{array}$ & $1.2 \cdot 10^{7} \mathrm{~m}^{2} \cdot \mathrm{m}^{-3}$ & 26 \\
\hline Cathode porosity, $\varepsilon$ & 0.37 & Estimated \\
\hline Cathode tortuosity, $\tau$ & 2 & Assumed \\
\hline LSCF particle radius & $1 \mu \mathrm{m}$ & Assumed \\
\hline Pore size, $d_{\mathrm{P}, \mathrm{C}}$ & $1 \mu \mathrm{m}$ & Assumed \\
\hline $\begin{array}{l}\mathrm{LSCF} / \text { gas phase DL } \\
\text { capacitance, } C_{\mathrm{DL}}^{\text {sur }}\end{array}$ & $100 \mathrm{~F} \cdot \mathrm{m}^{-2}$ & 26 \\
\hline $\begin{array}{l}\text { LSCF/YSZ Interfacial } \\
\text { DL }\end{array}$ & $(0.245 \cdot T / \mathrm{K}-185) \mathrm{F} \cdot \mathrm{m}^{-2}$ & 26 \\
\hline $\begin{array}{l}\text { capacitance, } C_{\mathrm{DL}}^{\mathrm{int}} \\
\text { Surface site density, } \\
\Gamma_{\mathrm{LSCF}}\end{array}$ & $1.0 \cdot 10^{-5} \mathrm{~mol} \cdot \mathrm{m}^{-2}$ & 26 \\
\hline Bulk density, $\rho_{\text {LSCF }}$ & $6890 \mathrm{~kg} \cdot \mathrm{m}^{-3}$ & 26 \\
\hline $\begin{array}{l}\text { Bulk vacancy/oxygen } \\
\text { fraction }\end{array}$ & $0.01 / 0.99$ & 26 \\
\hline
\end{tabular}

electrochemical operation, we solve both steady-state and transient problems. Electrochemical impedance spectra were simulated using a potential step and current relaxation technique. ${ }^{31}$ The impedance is obtained in the frequency domain by a Fourier transformation of the resulting time-domain traces of current and potential. For transient simulations (voltage and current density stability) at each time step, the solution (potential or current density) is determined by solving the transient system, and in the case of polarization curves (steadystate) calculations were carried out by solving the transient system to a steady-state, then the appropriate current density is obtained for a given overpotential.

\section{Model parameterization and elementary kinetic reaction mechanism}

Geometrical, kinetic and thermodynamic parameters employed in all simulations presented below are summarized in Tables I - III. The detailed explanations of the methods used to obtain these parameters are given in the following subsections.

Cell geometrical and electrochemical parameters. - Table I lists geometrical and electrochemical parameters that have been utilized in the electrochemical simulations. Since different literature-based experimental results were used to validate our model, Table I gives basic geometrical/structural parameters. When geometrical parameters were changed (e.g. thickness of electrode and/or electrolyte), they are given in the respective subsections. Due to the lack of information about some structural parameters (e.g. porosity, pore radius, etc.), some assumptions or estimations based upon previous work ${ }^{26,32-34}$ were made where these parameters were shown to be valid for a wide

\begin{abstract}
Table II. Thermodynamic data (enthalpies and entropies) for gasphase, surface and bulk species at $T=1023 \mathrm{~K}$. The temperaturedependent data for gas-phase species is calculated based upon NASA polynomials, the data for surface and bulk-species is assumed to be temperature-independent.
\end{abstract}

Species, $i \quad h_{i}\left(\mathrm{~kJ} \cdot \mathrm{mol}^{-1}\right) \quad s_{i}\left(\mathrm{~J} \cdot \mathrm{K}^{-1} \cdot \mathrm{mol}^{-1}\right) \quad$ Ref.

Gas-phase $(T=1023 \mathrm{~K}$

$\mathrm{H}_{2} \mathrm{~S}_{\text {gas }} \quad 8.6$

$\mathrm{H}_{2, \text { gas }} \quad 21.4$

$\mathrm{O}_{2, \text { gas }} \quad 23.5$

$\mathrm{H}_{2} \mathrm{O}_{\text {gas }}-241.9$

$\mathrm{SO}_{2, \text { gas }} \quad-261.1$

Ni surface

$\square_{\mathrm{Ni}}$

$\mathrm{O}_{\mathrm{Ni}}$

0

$\mathrm{H}_{\mathrm{Ni}}$

$-221.6$

$\mathrm{OH}_{\mathrm{Ni}}$

$$
-31.8
$$

$-192.7$

$\mathrm{H}_{2} \mathrm{O}_{\mathrm{Ni}}$

$-273.2$

$\mathrm{H}_{2} \mathrm{~S}_{\mathrm{Ni}}$

$-43.2^{16}$

$\mathrm{HS}_{\mathrm{Ni}}$

$-132.0^{16}$

$\mathrm{SO}_{2, \mathrm{Ni}}$

$-485.9^{19}$

$\mathrm{SO}_{\mathrm{Ni}}$

$-295.0^{19}$

$\mathrm{S}_{\mathrm{Ni}}$

$f\left(\theta_{\mathrm{s}}\right)$

253.5
166.9
244.4
233.7
306.9

0
38.9
40.7
106.4
130.7
0
0
0
0
$52.0^{20,38}$

37

37

37

YSZ surface

$\begin{array}{cc}\square_{\mathrm{YSZ}} & 0 \\ \mathrm{O}_{\mathrm{YSZ}}^{2-} & -236.4 \\ \mathrm{H}_{2} \mathrm{O}_{\mathrm{YSZ}} & -273.0 \\ \mathrm{OH}_{\mathrm{YSZ}}^{1-} & -282.5 \\ \text { Bulk species } & \\ \mathrm{O}_{\mathrm{OYSZ}}^{\times} & -236.4 \\ \mathbf{V}_{\mathrm{YSZ}}^{\ddot{\mathrm{YSZ}}} & 0\end{array}$

\section{0}

0

97.9

67.0

0

0
Reference species 35 35
See text for detailed explanation

Reference species 35

35

35

35

Reference species

range of operating conditions. Table I presents first the data for the $\mathrm{Ni} / Y S Z$ phase including electrical double layer capacitance estimated based upon impedance simulations, second, data for the YSZ electrolyte (ionic conductivity, surface site density and bulk properties) and third, information about geometrical and electrical parameters of the mixed ionic-electronic conductor LSCF phase. The latter data was thoroughly described elsewhere. ${ }^{26}$

Heterogeneous chemistry on Ni surface and charge-transfer process: Elementary kinetic reaction mechanism.- Since the gas-phase composition used in the present study mainly consists of $\mathrm{H}_{2} / \mathrm{H}_{2} \mathrm{O}$ gases, a previously developed and validated reaction mechanism for $\mathrm{H}_{2}$ oxidation at Ni/YSZ SOFC anodes was used..$^{35,36}$ The additional thermodynamic and kinetic parameters of sulfur formation/oxidation derived in the present work are described below in more detail. The thermodynamic data of all species that are emerging during the formation and oxidation reactions form the basis for thermodynamically consistent kinetic simulations. This data is summarized in Table II. The anode system is assumed to consist of five gas-phase species $\left(\mathrm{H}_{2} \mathrm{O}_{\text {gas }}, \mathrm{H}_{2, \text { gas }}, \mathrm{H}_{2} \mathrm{~S}_{\text {gas }}, \mathrm{O}_{2, \text { gas }}, \mathrm{SO}_{2 \text {,gas }}\right)$, ten $\mathrm{Ni}$ surface species $\left(\square_{\mathrm{Ni}}\right.$, $\mathrm{O}_{\mathrm{Ni}}, \mathrm{H}_{\mathrm{Ni}}, \mathrm{OH}_{\mathrm{Ni}}, \mathrm{H}_{2} \mathrm{O}_{\mathrm{Ni}}, \mathrm{H}_{2} \mathrm{~S}_{\mathrm{Ni}}, \mathrm{HS}_{\mathrm{Ni}}, \mathrm{SO}_{2, \mathrm{Ni}}, \mathrm{SO}_{\mathrm{Ni}}, \mathrm{S}_{\mathrm{Ni}}$, four YSZ surface species $\left(\square_{\mathrm{YSZ}}, \mathrm{O}_{\mathrm{YSZ}}^{2-}, \mathrm{H}_{2} \mathrm{O}_{\mathrm{YSZ}}, \mathrm{OH}_{\mathrm{YSZ}}^{-}\right)$, and two bulk lattice YSZ species $\left(\mathrm{O}_{\mathrm{O} Y S Z}^{\times}, \mathrm{V}_{\mathrm{YSZ}}^{*}\right)$. Here, $\square_{\mathrm{Ni}}$ and $\square_{\mathrm{YSZ}}$ represent free surface adsorption sites and are taken as reference species, thus, their enthalpy and entropy are set to zero.

Enthalpies and entropies of the gas phase species were calculated using NASA polynomials that account for their temperature dependency. ${ }^{37}$ The values of the thermodynamic parameters of $\mathrm{O}_{\mathrm{Ni}}$, $\mathrm{H}_{\mathrm{Ni}}, \mathrm{OH}_{\mathrm{Ni}}$ and $\mathrm{H}_{2} \mathrm{O}_{\mathrm{Ni}}$ were taken from modeling studies previously performed in our group..$^{35,36}$ It was assumed that the presence of additional surface species does not affect the values of these thermodynamic parameters. 
Table III. Reaction mechanism used in the present study. Ni and YSZ surface site densities are $6.1 \cdot 10^{-5} \mathrm{~mol} \cdot \mathrm{m}^{-2}$ and $1.3 \cdot 10^{-5} \mathrm{~mol} \cdot \mathrm{m}^{-2}$, respectively. Symmetry factor of the charge-transfer reaction is set to 0.5 . The parameters are: pre-exponential factor $k^{\mathbf{0}}$, sticking coefficient $s_{\mathrm{i}}{ }^{0}$, activation energy barrier $E^{\text {act }}$. The symbols $\square_{\mathrm{Ni}}$ and $\square_{\mathrm{YSZ}}$ represent free active surface sites on Ni and YSZ, respectively. The table shows only the rate coefficients for the forward reaction. The respective rate coefficients for the reverse reactions are derived based on thermodynamic consistency using the data shown in Table II.

\begin{tabular}{|c|c|c|c|c|}
\hline No. & Reaction & $k^{0}\left(\right.$ or $\left.s_{i}^{0}\right)$ & $E^{\mathrm{act}}\left(\mathrm{kJ} \cdot \mathrm{mol}^{-1}\right)$ & Ref. \\
\hline \multicolumn{5}{|c|}{ Ni surface } \\
\hline R1 & $\mathrm{H}_{2, \mathrm{~g}}+2 \square_{\mathrm{Ni}} \rightleftharpoons 2 \mathrm{H}_{\mathrm{Ni}}$ & $9.80 \cdot 10^{17} \mathrm{~cm}^{4} \cdot \mathrm{mol}^{-2} \cdot \mathrm{s}^{-1}$ & 0 & 35 \\
\hline R2 & $\mathrm{H}_{2} \mathrm{O}_{\mathrm{g}}+\square_{\mathrm{Ni}} \rightleftharpoons \mathrm{H}_{2} \mathrm{O}_{\mathrm{Ni}}$ & $1.4 \cdot 10^{10} \mathrm{~cm}^{2} \cdot \mathrm{mol}^{-1} \cdot \mathrm{s}^{-1}$ & 0 & 35 \\
\hline R3 & $\mathrm{H}_{\mathrm{Ni}}+\mathrm{O}_{\mathrm{Ni}} \rightleftharpoons \mathrm{OH}_{\mathrm{Ni}}+\square_{\mathrm{Ni}}$ & $5.0 \cdot 10^{22} \mathrm{~cm}^{2} \cdot \mathrm{mol}^{-1} \cdot \mathrm{s}^{-1}$ & 97.9 & 35 \\
\hline R4 & $\mathrm{H}_{\mathrm{Ni}}+\mathrm{OH}_{\mathrm{Ni}} \rightleftharpoons \mathrm{H}_{2} \mathrm{O}_{\mathrm{Ni}}+\square_{\mathrm{Ni}}$ & $3.0 \cdot 10^{20} \mathrm{~cm}^{2} \cdot \mathrm{mol}^{-1} \cdot \mathrm{s}^{-1}$ & 42.7 & 35 \\
\hline R5 & $\mathrm{H}_{2} \mathrm{O}_{\mathrm{Ni}}+\mathrm{O}_{\mathrm{Ni}} \rightleftharpoons 2 \mathrm{OH}_{\mathrm{Ni}}$ & $5.42 \cdot 10^{23} \mathrm{~cm}^{2} \cdot \mathrm{mol}^{-1} \cdot \mathrm{s}^{-1}$ & 209.4 & 35 \\
\hline R6 & $\mathrm{H}_{2} \mathrm{~S}_{\mathrm{g}}+\square_{\mathrm{Ni}} \rightleftharpoons \mathrm{H}_{2} \mathrm{~S}_{\mathrm{Ni}}$ & $s_{i}^{0}=0.5$ & 0 & Assumed \\
\hline R7 & $\mathrm{H}_{2} \mathrm{~S}_{\mathrm{Ni}}+\square_{\mathrm{Ni}} \rightleftharpoons \mathrm{HS}_{\mathrm{Ni}}+\mathrm{H}_{\mathrm{Ni}}$ & $1.0 \cdot 10^{22} \mathrm{~cm}^{2} \cdot \mathrm{mol}^{-1} \cdot \mathrm{s}^{-1}$ & 14.5 & 16 \\
\hline R8 & $\mathrm{HS}_{\mathrm{Ni}}+\square_{\mathrm{Ni}} \rightleftharpoons \mathrm{H}_{\mathrm{Ni}}+\mathrm{S}_{\mathrm{Ni}}$ & $1.0 \cdot 10^{22} \mathrm{~cm}^{2} \cdot \mathrm{mol}^{-1} \cdot \mathrm{s}^{-1}$ & 10.6 & 16 \\
\hline R9 & $\mathrm{SO}_{\mathrm{Ni}}+\square_{\mathrm{Ni}} \rightleftharpoons \mathrm{S}_{\mathrm{Ni}}+\mathrm{O}_{\mathrm{Ni}}$ & $1.0 \cdot 10^{22} \mathrm{~cm}^{2} \cdot \mathrm{mol}^{-1} \cdot \mathrm{s}^{-1}$ & 158.2 & 19 \\
\hline R10 & $\mathrm{SO}_{\mathrm{Ni}}+\mathrm{O}_{\mathrm{Ni}} \rightleftharpoons \mathrm{SO}_{2, \mathrm{Ni}}+\square_{\mathrm{Ni}}$ & $1.0 \cdot 10^{22} \mathrm{~cm}^{2} \cdot \mathrm{mol}^{-1} \cdot \mathrm{s}^{-1}$ & 61.8 & 19 \\
\hline R11 & $\mathrm{SO}_{2, \mathrm{Ni}} \rightleftharpoons \mathrm{SO}_{2, \mathrm{~g}}+\square_{\mathrm{Ni}}$ & $1.0 \cdot 10^{10} \mathrm{~s}^{-1}$ & 0 & 19 \\
\hline \multicolumn{5}{|c|}{ YSZ surface } \\
\hline R12 & $\mathrm{H}_{2} \mathrm{O}_{\mathrm{g}}+\square_{\mathrm{YSZ}} \rightleftharpoons \mathrm{H}_{2} \mathrm{O}_{\mathrm{YSZ}}$ & $6.595 \cdot 10^{11} \mathrm{~cm}^{2} \cdot \mathrm{mol}^{-1} \cdot \mathrm{s}^{-1}$ & 0 & 35 \\
\hline R13 & $\mathrm{H}_{2} \mathrm{O}_{\mathrm{YSZ}}+\mathrm{O}_{\mathrm{YSZ}}^{2-} \rightleftharpoons 2 \mathrm{OH}_{\mathrm{YSZ}}^{1-}$ & $1.6 \cdot 10^{25} \mathrm{~cm}^{2} \cdot \mathrm{mol}^{-1} \cdot \mathrm{s}^{-1}$ & 164.0 & 35 \\
\hline R14 & $\mathrm{O}_{\mathrm{OYSZ}}^{\times}+\square_{\mathrm{YSZ}} \rightleftharpoons \mathrm{V}_{\mathrm{YSZ}}{ }^{*}+\mathrm{O}_{\mathrm{YSZ}}^{2-}$ & $1.6 \cdot 10^{22} \mathrm{~cm}^{2} \cdot \mathrm{mol}^{-1} \cdot \mathrm{s}^{-1}$ & 91.0 & 35 \\
\hline \multicolumn{5}{|c|}{ Charge-transfer reaction } \\
\hline
\end{tabular}

The enthalpies of $\mathrm{H}_{2} \mathrm{~S}_{\mathrm{Ni}}$ and $\mathrm{HS}_{\mathrm{Ni}}$ were derived based on a density functional theory study by Alfonso who carried out calculations on $\mathrm{Ni}(111)$ surfaces. ${ }^{16}$ Similarly, the enthalpies of $\mathrm{SO}_{2, \mathrm{Ni}}$ and $\mathrm{SO}_{\mathrm{Ni}}$ were derived based on DFT calculations by Galea et al. for Ni(111) oriented plane as well. ${ }^{19}$ Based on the species' binding energies given in these studies, the enthalpies of the adsorbates were calculated as the difference between adsorption energy of the adsorbate species and the sum of the species' gas phase enthalpy and the energy of the bare $\mathrm{Ni}$ surface. Since SO und HS are not stable in the gas phase and thus no thermodynamic data is available, their enthalpies were derived based upon the corresponding reaction enthalpy for their formation.

As there was no literature data available for these species' entropies, and in order to reduce the number of fitting parameters, their values were set to zero. However, if further molecular details (vibrational frequencies from elaborated ab initio calculations) of adsorbed species become available the refinement of the entropy values might certainly be useful. Regarding the thermodynamic data of nickel-adsorbed sulfur, we assume a coverage-dependent enthalpy, but coverage-independent entropy, as it was already suggested previously. ${ }^{17,20,23}$

For the entropy of sulfur, we adopted the value of $52 \mathrm{~J} \cdot \mathrm{K}^{-1} \cdot \mathrm{mol}^{-1}$ calculated by Monder et al. who used DFT calculations to examine vibrational modes and frequencies from finite difference approximation of the Hessian matrix of adsorbed species on the Ni surface. ${ }^{20}$ This value is also in accordance with the value derived from an experimental study by McCarty et al. ${ }^{38}$ The derivation of $h\left(\mathrm{~S}_{\mathrm{Ni}}\right)$ is explained in the subsequent section.

In this study, all chemical reactions were resolved into elementary steps. The elementary reactions composing the overall electrochemical reaction mechanism are listed in Table III. The rate constants of the forward reactions were calculated via an Arrhenius expression. For the reverse reactions, the rate constants were calculated in a thermodynamically consistent way from the enthalpies and entropies given in Table II.

The (electro-)chemical mechanism used in the present work includes eleven Ni surface reactions (R1 - R11), three YSZ surface reactions (R12 - R14) and one charge transfer reaction $(\mathrm{C} 1)$. The previously validated electrochemical mechanism for $\mathrm{H}_{2}$ oxidation serves as a basis for the electrochemical mechanism derived in this paper. ${ }^{35,36}$ It is assumed that the presence of the sulfur-containing surface species does not have an influence on the kinetic parameters of $\mathrm{H}_{2}$ oxidation.
Thus, for the elementary reactions R1 - R5, R12 - R14 and C1, activation energy barriers along with pre-exponential factors are assumed to have the previously derived values. To the best of our knowledge, there is no validated reaction mechanism available in literature for sulfur formation and its removal. Hence, the extension of the validated reaction mechanism is based on elementary steps suggested in Refs. 16-19. It consists of the following steps: $\mathrm{H}_{2} \mathrm{~S}$ adsorption (R6), $\mathrm{H}_{2} \mathrm{~S}$ dissociation (R7 - R8), $\mathrm{SO}_{2}$ formation (R9-R10), and $\mathrm{SO}_{2}$ desorption (R11). The adsorption of $\mathrm{H}_{2} \mathrm{~S}$ is assumed to be molecular and fast, ${ }^{39}$ thus the sticking coefficient was set to 0.5 and the activation energy barrier was set to 0 . As the values for the activation energy barriers of the $\mathrm{H}_{2} \mathrm{~S}$ dissociation and $\mathrm{SO}_{2}$ formation reactions, we used the ones calculated via DFT in Refs. 18 and 19, respectively. Due to a lack of literature data about entropies of different adsorbed species used in the reactions $\mathrm{R} 7$ - R11, we used the commonly accepted assumption that the attempt frequency at the surface is equal to the vibrational frequency of the adsorbate, which leads to a pre-exponential factor of $1 \cdot 10^{22} \mathrm{~cm}^{2} \cdot \mathrm{mol}^{-1} \cdot \mathrm{s}^{-1}$ for second order reactions. ${ }^{33}$

In the present reaction mechanism, possible direct electrochemical sulfur oxidation is not explicitly included due to only limited information in literature about its occurrence and kinetics. Moreover, electrochemical sulfur oxidation would require simultaneous mass and charge transfer and thus, could possibly be further resolved into additional processes. For this reason and also in order to reduce the number of fitting parameters, in the present model sulfur oxidation is modeled by a heterogeneous catalytic pathway. However, if elaborate first principles investigations should provide for a more profound mechanistic understanding, the extension of the present reaction mechanism could certainly be a fruitful approach.

In a different study, Appari et al. have reported four additional chemical reactions, where different sulfur-containing species participate. ${ }^{40}$ In their kinetic model of biogas steam reforming on $\mathrm{Ni}$ catalysts the following reactions are included:

$$
\begin{gathered}
\mathrm{HS}_{\mathrm{Ni}}+\mathrm{O}_{\mathrm{Ni}} \rightleftharpoons \mathrm{SO}_{\mathrm{Ni}}+\mathrm{H}_{\mathrm{Ni}}, \\
\mathrm{H}_{2} \mathrm{~S}_{\mathrm{Ni}}+\mathrm{O}_{\mathrm{Ni}} \rightleftharpoons \mathrm{HS}_{\mathrm{Ni}}+\mathrm{OH}_{\mathrm{Ni}}, \\
\mathrm{S}_{\mathrm{Ni}}+\mathrm{OH}_{\mathrm{Ni}} \rightleftharpoons \mathrm{SO}_{\mathrm{Ni}}+\mathrm{H}_{\mathrm{Ni}}, \\
\mathrm{S}_{\mathrm{Ni}}+\mathrm{H}_{2} \mathrm{O}_{\mathrm{Ni}} \rightleftharpoons \mathrm{HS}_{\mathrm{Ni}}+\mathrm{OH}_{\mathrm{Ni}} .
\end{gathered}
$$


All of these processes involve simultaneous bond-breaking and bondmaking. However, they are not explicitly included in our model, since all of them are represented by the elementary reactions comprised in our mechanism if the bond-breaking and bond-making events are assumed to happen consecutively. For example, reaction 3 can be described by the dissociation of the HS radical (R8) and the subsequent recombination of atomic sulfur and oxygen (R9). The other reactions 4-6 can also be subdivided analogously. However, the extension of our developed chemical mechanism by the reactions 3-6 could be considered, when detailed ab initio calculations will be available showing only one transition state along the respective minimum energy pathway in one of the reactions 3-6.

Heterogeneous chemistry on Ni surface and charge-transfer process: Coverage dependency of the enthalpy of the adsorbed sulfur species. - The effect of the repulsive lateral interactions between the sulfur surface atoms becomes notable at high coverage that emerges due to the strong adsorbate-surface interactions of sulfur and nickel. To date, in most surface science studies these predominantly repulsive lateral interactions were modeled by coverage-dependent activation energy barriers. ${ }^{3,41,42}$ However, in the present work we employed a coverage-dependent surface enthalpy $h\left(\mathrm{~S}_{\mathrm{Ni}}\right)$, as it has already been suggested previously. ${ }^{17,20,23}$ This approach has already been used in prior microkinetic modeling studies in which simple linear correlations have been employed to model adsorption enthalpies as a function of coverage. ${ }^{43-46}$

In order to determine the exact coverage dependency of $h\left(\mathrm{~S}_{\mathrm{Ni}}\right)$, we reproduced experimental data published by Alstrup et al. ${ }^{23}$ In their paper, the authors measured the fractional coverage of sulfur on nickel for different gas phase concentrations of $\mathrm{H}_{2} \mathrm{~S}$ in the temperature range between $800 \mathrm{~K}$ and $1150 \mathrm{~K}$. As inlet gas, they used hydrogen gas with different trace amounts of $\mathrm{H}_{2} \mathrm{~S}$. In order to compare our simulations with the experimental data, we have calculated the sulfur coverage on the Ni surface using the experimental condition described in Ref. 23. The originally given fractional sulfur coverage is converted into the real coverage by means of the sulfur saturation coverage $\theta_{\max }(S)$ that was experimentally determined to be $0.5 \mathrm{ML}{ }^{47}$ The thermodynamic and kinetic data of all species and reactions (Table II and III) are utilized as the base parameter set in our calculations. The value of $h\left(\mathrm{~S}_{\mathrm{Ni}}\right)$ was fitted to reproduce the given experimental data. Fig. 2 compares the computed equilibrium coverage of sulfur for a temperature range from $800 \mathrm{~K}$ to $1150 \mathrm{~K}$ with the experimental measurements by Alstrup et al. As illustrated in Fig. 2, the proposed surface reaction mechanism of sulfur formation matches the experimental observation well after calibration.

The determined coverage-dependent values of $h\left(\mathrm{~S}_{\mathrm{Ni}}\right)$, based upon equilibrium calculations shown in Fig. 2, are plotted in Fig. 3. Based on the obtained results, a clear linear correlation between enthalpy and

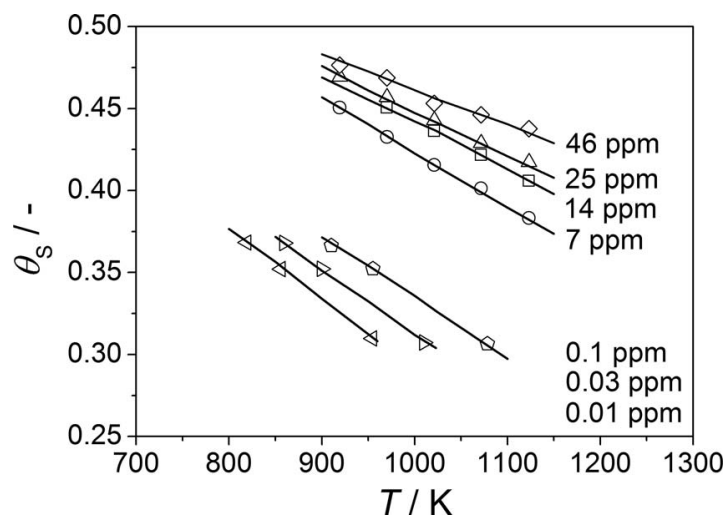

Figure 2. Comparison between experimental and simulated sulfur surface coverage on $\mathrm{Ni}$ as a function of temperature for different $\mathrm{H}_{2} \mathrm{~S}$ gas concentrations. Experimental data are taken from Ref. 23

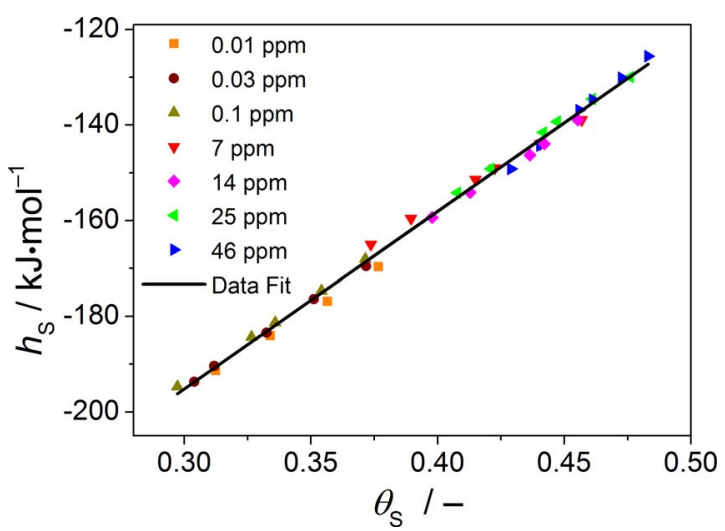

Figure 3. Values of the enthalpy of nickel-adsorbed sulfur obtained through fitting of the experimental results shown in Fig. 2. Different gas phase concentrations of $\mathrm{H}_{2} \mathrm{~S}$ are represented by different colors and symbols. The resulting linear regression of the illustrated values is shown as a solid line. $R^{2}=0.995$.

surface sulfur coverage can be perceived. This behavior is similar to the results of previous studies by Grabow et al. ${ }^{44}$ and Miller et al. ${ }^{45}$ who investigated the relation between binding energies and coverage for different adsorbate/metal systems. They have found that the binding energy of adsorbates increases linearly with surface coverage above a certain threshold coverage $\left(\theta_{0}\right)$. Based upon these findings, in the present work the following linear relation between the enthalpy of sulfur and its coverage has been derived

$h\left(\mathrm{~S}_{\mathrm{Ni}}\right)=\left\{\begin{array}{r}-202 / \mathrm{kJ} \cdot \mathrm{mol}^{-1}, \text { for } \theta_{\mathrm{S}}<0.28 \\ -202+370.99 \cdot\left(\theta_{\mathrm{S}}-0.28\right) / \mathrm{kJ} \cdot \mathrm{mol}^{-1}, \text { for } \theta_{\mathrm{S}} \geq 0.28\end{array}\right.$

As it is revealed by Eq. 7, the threshold coverage is $\theta_{0}=0.28$. This is a physically meaningful description of the coverage dependency of sulfur, since in the limit of low coverage the lateral adsorbateadsorbate interactions are weak and the adsorbates do not share any metal atoms, thus, below the threshold coverage, $h\left(\mathrm{~S}_{\mathrm{Ni}}\right)$ should be constant.

The obtained enthalpy for threshold coverage $\left(-202 \mathrm{~kJ} \cdot \mathrm{mol}^{-1}\right)$ is consistent with the value calculated using DFT for sulfur on a Ni(111) surface by Wang et al. ${ }^{17}$ Based on a binding energy of $-1.96 \mathrm{eV}$, the lowest reported value, a sulfur surface enthalpy of $-202 \mathrm{~kJ} \cdot \mathrm{mol}^{-1}$ can be derived. Furthermore, the authors reported an increase in binding energy starting at real sulfur coverage of $0.25 \mathrm{ML}$ which is also in good agreement with the threshold coverage used in Eq. 7.

In summary, based on experimental results available in literature, we have derived a physically meaningful relation between the enthalpy of nickel-adsorbed sulfur and its coverage. We have shown the validity of the developed reaction mechanism for a purely chemical system within the temperature range $800 \mathrm{~K}-1150 \mathrm{~K}$ and for gas phase concentrations over more than three orders of magnitude $(0.01 \mathrm{ppm}$ - $46 \mathrm{ppm})$. In the following electrochemical simulations, $h\left(\mathrm{~S}_{\mathrm{Ni}}\right)$ is calculated accordingly to Eq. 7 .

\section{Results and Discussion}

In order to verify our developed model, it was validated against various literature sources under a wide range of conditions. Firstly, impedance spectra of anode-supported cells recorded by Yang et al. were reproduced for a $\mathrm{H}_{2} \mathrm{~S}$ gas concentration of $1 \mathrm{ppm}$ at $1023 \mathrm{~K} .{ }^{9}$ These impedance spectra simulations also served as an initial calibration of the model parameters listed in Table I. Subsequently, current density stability tests of electrolyte-supported cells by Zha et al. were simulated for a higher temperature of $1073 \mathrm{~K}$ and $\mathrm{H}_{2} \mathrm{~S}$ concentrations as high as $50 \mathrm{ppm} .{ }^{5}$ Eventually, relative power output drops for electrolyte-supported cells were calculated for $\mathrm{H}_{2} \mathrm{~S}$ concentrations between $1-10 \mathrm{ppm}$ published by Cheng et al. in order to reproduce the 


$\begin{aligned} & \text { Table IV. Model parameters used to reproduce the experimental } \\
& \text { results from Yang et al. }\end{aligned}$
\begin{tabular}{lcc} 
Parameter & Value & Reference \\
\hline Anode thickness, $d_{\mathrm{Ni} / \mathrm{YSZ}}$ & $500 \mu \mathrm{m}$ & 9 \\
Anode TPB length & $2.3 \cdot 10^{12} \mathrm{~m} \cdot \mathrm{m}^{-2}$ & Fit \\
Electrolyte thickness, $d_{\mathrm{YSZ}}$ & $10 \mu \mathrm{m}$ & 9 \\
Cathode thickness, $d_{\mathrm{LSCF}}$ & $30 \mu \mathrm{m}$ & 9
\end{tabular}

saturation effect and the different behavior in power output drop for galvanostatic and potentiostatic operation mode. ${ }^{6}$

Modeling of anode-supported SOFC performance.- Firstly, in order to obtain a base parameter set for the consecutive simulations of sulfur poisoning, the polarization curve for a system without the presence of sulfur was simulated. As an example to illustrate the model, a particular MEA structure used by Yang et al. ${ }^{9}$ is adapted. Yang et al. have investigated anode-supported cells with a Ni-YSZ thick anode, LSCF cathode and a base anode fuel mixture of 50\% $\mathrm{H}_{2} / 1.5 \% \mathrm{H}_{2} \mathrm{O} / 48.5 \% \mathrm{~N}_{2}$. Using our model with the parameter set shown in Tables I - IV, the polarization curve as well as power density curve have been reproduced in Figure 4 (depicted as full lines). Moreover, the I-V and power density curve for the same system exposed to $1 \mathrm{ppm} \mathrm{H}_{2} \mathrm{~S}$ have been simulated and are shown in the figure (dashed lines). It can be seen that the power characteristics of the sulfur-poisoned cell are predicted to decrease drastically.

This particular cell shows relatively high transport resistance at voltages below $0.45 \mathrm{~V}$ leading to an asymmetric power density curve. Thus, in order to achieve the shown agreement, some parameters of the model have been tuned to represent this button cell, in particular, the triple phase boundary (TPB) length of the anode, the interfacial double layer capacitance, and the geometrical parameters of the gas channel over the anode were fitted to the experimental results. As the interfacial double layer capacitance cannot be derived from the polarization curve, it was fitted to the non-sulfur impedance spectra shown in Fig. 5. The same parameter set was subsequently used in all impedance spectra simulations in the presence of hydrogen sulfide.

Figure 5 shows the comparison between experimental and simulated electrochemical impedance spectra for systems before and after exposure to $1 \mathrm{ppm}_{2} \mathrm{~S}$ at various current densities and $T=1023 \mathrm{~K}$. The experimental results have shown the trend of a smaller relative increase in cell resistance for higher current densities. ${ }^{6}$ As, the simulated Nyquist plots (left panel) are in very good agreement with the experimental results, it can be concluded that our model is able to reproduce this characteristic poisoning behavior.

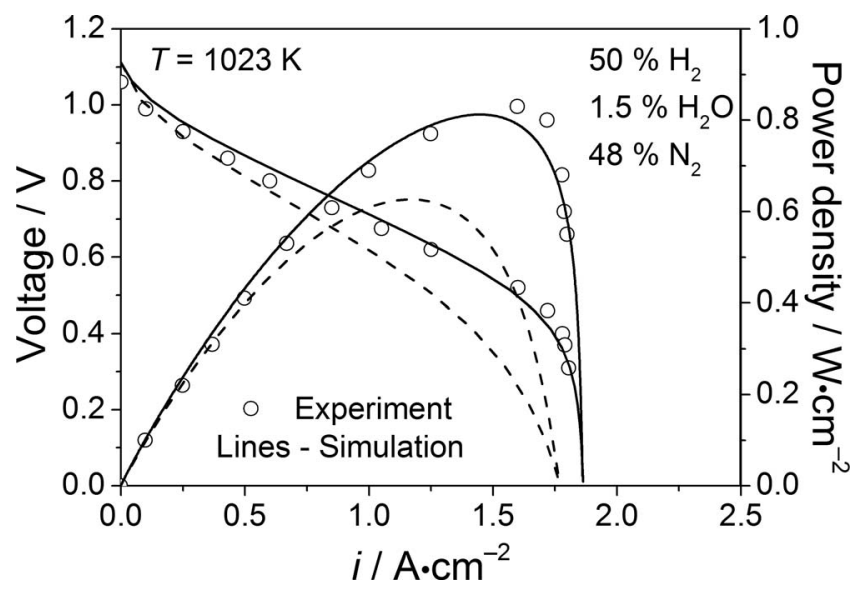

Figure 4. Comparison of the model (solid lines) and experimental measurements (open symbols) for a button cell operating on humidified hydrogen at $T$ $=1023 \mathrm{~K}$. The dashed lines show the simulated I-V and power density curve for the system exposed to $1 \mathrm{ppm} \mathrm{H}_{2} \mathrm{~S}$. Experimental data are taken from Ref. 9.
The influence of an exposure of the system to $\mathrm{H}_{2} \mathrm{~S}$ is also clearly demonstrated by the Bode plots in Figure 5 (right panel). It can be seen that at frequencies of about $10^{1} \mathrm{~Hz}$, where commonly surface processes take place, ${ }^{48,49}$ the presence of $\mathrm{H}_{2} \mathrm{~S}$ leads to a significant increase of the imaginary part of the impedance. This increase occurs at all current densities, however, the increase is most pronounced for $i$ $=200 \mathrm{~mA} \cdot \mathrm{cm}^{-2}$. Moreover, a small upwards shift of the initial Bode plot after exposure to $\mathrm{H}_{2} \mathrm{~S}$ can be observed in the low frequency region between $10^{-3}$ and $10^{-1} \mathrm{~Hz}$ which corresponds to resistance due to gas transport over the anode surface in the supply volume, also referred to as gas concentration impedance. ${ }^{29}$ It should be noted that due to insufficient data about the increase of Ohmic resistance in impedance spectra we have modeled it by employing additional contact resistance with $r_{0}$ equals to $7.8 \cdot 10^{-5} \Omega \cdot \mathrm{m}^{2}$ and a slope of $-1.03 \cdot 10^{-3} \mathrm{~K}^{-1}$. This is certainly a reasonable assumption, since, as it was shown in some recent experimental studies even for considerably higher $\mathrm{H}_{2} \mathrm{~S}$ concentrations (up to $100 \mathrm{ppm}$ ) sulfur poisoning does not have a significant influence on the Ohmic resistance. ${ }^{7}$

Modeling of electrolyte-supported SOFC performance: Current density stability tests. - The following results are shown in order to demonstrate the capability of the model toward electrolyte-supported cell performance. Zha et al. have examined Ni/YSZ-based cells with LSM cathodes in a fuel mixture of $50 \% \mathrm{H}_{2} / 1.5 \% \mathrm{H}_{2} \mathrm{O} / 48.5 \% \mathrm{~N}_{2}$ and various trace amounts of $\mathrm{H}_{2} \mathrm{~S}$ at $1073 \mathrm{~K}$. The parameters used in the corresponding simulations are listed in Table V. The base parameter set including triple phase boundary length and gas channel geometry was determined via the reproduction of a polarization curve of a non-sulfur system from Ref. 5 (not shown here). Since Zha et al. employed LSM as cathode of the investigated cell, in our study the electrochemical oxygen reduction process was modeled by the ButlerVolmer equation.

In Figure 6 comparisons between the experimental and simulated results of the current density stability during sulfur poisoning and recovery process are shown. As can be seen in Figure 6 transient calculations can be performed with our model, so that it is run with time-varying input monitoring different electrochemical performance. This is especially valuable data, since it provides the possibility to reproduce degradation phenomena of the cell in time. In contrast to the study of Yang et al. who observed stable long-term performance for low $\mathrm{H}_{2} \mathrm{~S}$ gas phase concentrations, Zha et al. reported slower, irreversible second stage degradation. Recently, Kishimoto et al. have used thermodynamic calculations to shed light on the processes underlying irreversible degradation. They showed that an increasing oxygen potential entails enhanced sulfur diffusion into nickel. ${ }^{11}$ As a result, increased sintering of the nickel particles leads to their detachment from the original position and an associated change in TPB length. However, due to limited data on the actual rate and type of mentioned processes, we modeled the second stage degradation via a continuous reduction of TPB length. In the present model we assume that the TPB of the anode decreases linearly by the following function

$$
l_{\mathrm{Ni} / \mathrm{YSZ}}^{\mathrm{V}}=l_{\mathrm{Ni} / \mathrm{YSZ}, 0}^{\mathrm{V}} \cdot e^{-\tau} \cdot\left(1-0.12 \cdot \theta\left(\mathrm{S}_{\mathrm{Ni}}\right)\right),
$$

where $l_{\mathrm{Ni} / \mathrm{YSZ}}^{\mathrm{V}}$ is the TPB length of the Ni/YSZ phase, a subscript ${ }_{0}$ denotes the initial TPB length, and $\tau$ is the power coefficient resulting of time in hours divided by $3600 \mathrm{~h}$. In Fig. $6 \mathrm{a} \mathrm{a} \mathrm{H}_{2} \mathrm{~S}$ concentration of $2 \mathrm{ppm}$ was introduced into the fuel at a cell voltage of $0.7 \mathrm{~V}$, in Fig. $6 \mathrm{~b}$ $50 \mathrm{ppm} \mathrm{H}_{2} \mathrm{~S}$ was added at a cell voltage of $0.6 \mathrm{~V}$. At the beginning of the simulation, the cell is operating in steady-state at a current density of about $250 \mathrm{~mA} \cdot \mathrm{cm}^{-2}$. After a certain period of time ( 10 hours for $2 \mathrm{ppm}$ and 25 hours for $50 \mathrm{ppm}) \mathrm{H}_{2} \mathrm{~S}$ was introduced to the system, which leads to a decrease in current density from $250 \mathrm{~mA} \cdot \mathrm{cm}^{-2}$ to $216 \mathrm{~mA} \cdot \mathrm{cm}^{-2}(2 \mathrm{ppm})$ and to $207 \mathrm{~mA} \cdot \mathrm{cm}^{-2}$ (50 ppm) with a subsequent slow decrease over the whole experimental monitoring time. In both cases the initial cell current density drop was successfully modeled by sulfur chemisorption at the nickel surface. The simulated initial drop is completed after approximately 10 min depending on the $\mathrm{H}_{2} \mathrm{~S}$ concentration in the gas phase. The consecutive current density 

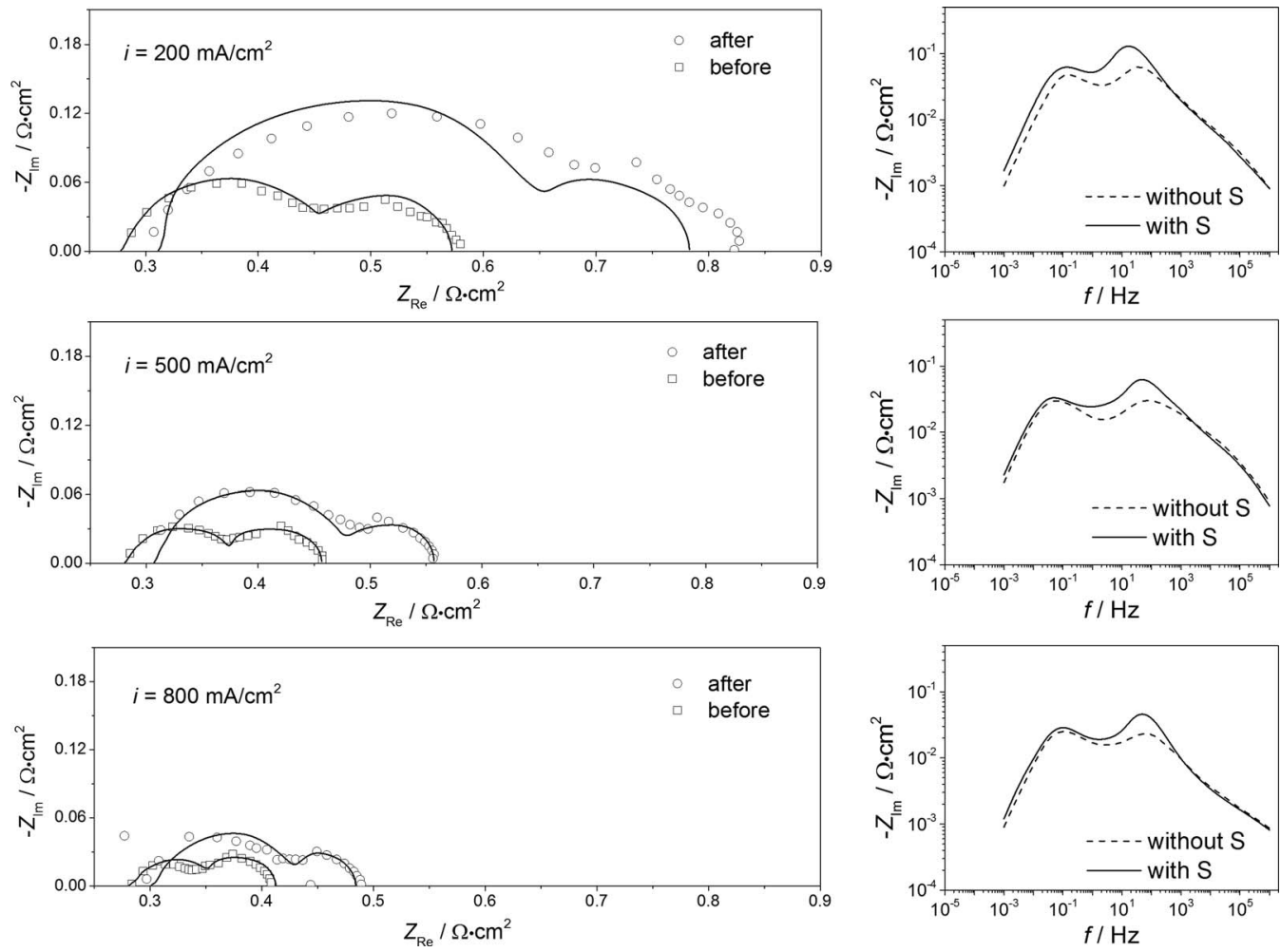

Figure 5. Nyquist (left panel) and Bode (right panel) plots of impedance spectra at a temperature of $1023 \mathrm{~K}$ and pressure of 1 atm before and after exposure to $1 \mathrm{ppm} \mathrm{H}_{2} \mathrm{~S}$ at various current densities. The experimental results are taken from Ref. 9. The left panel of the figure represents Nyquist plots of experiments and simulations. The right panel shows Bode plots of the imaginary part of the simulated complex impedance. There is no experimental data given for the Bode plots, thus, only simulation results are depicted.

decrease is initiated by a TPB reduction described by Eq. 8 . The model reveals the average degradation rate to be approximately 0.2 $\mathrm{mA} \cdot \mathrm{cm}^{-2} \cdot \mathrm{h}^{-1}$.

The developed sulfur poisoning mechanism has been tested toward the recovery of the cell after operation with $\mathrm{H}_{2} \mathrm{~S}$. The same Figs. 6(a,b) illustrate the recovery of the cell after operation with $2 \mathrm{ppm}$ (after $30 \mathrm{~h}$ ) and $50 \mathrm{ppm}$ (after $145 \mathrm{~h}$ ) of $\mathrm{H}_{2} \mathrm{~S}$. In the case of lower hydrogen sulfide concentration we obtained slower recovery in comparison to the experimental data, and for $50 \mathrm{ppm}$ the predicted recovery of the cell operation is slightly faster, however, after certain period of time the simulated and experimental current densities match well for both concentrations. However, the deviation in Fig. 6a demonstrates that further studies are required for a wide range of operating conditions in order to resolve the detailed processes occurring during recovery and the refinement of the corresponding thermodynamic and kinetic data.

In addition, the predictions of further cell degradation are shown (dashed line in both figures), which indicate that the cell current density progressively decreases mainly due to TPB reduction. As it is reported in the prior literature section, the continuous decrease of SOFC performance could be observed over longer time periods as the anode is exposed to hydrogen sulfide. ${ }^{15}$ Thus, in order to include the $2^{\text {nd }}$ stage degradation over a longer period of exposure time, an

Table V. Model parameters used to reproduce the experimental results from Zha et al. ${ }^{5}$
Parameter

Anode thickness, $d_{\mathrm{Ni} / \mathrm{YSZ}}$

Anode TPB length

Electrolyte thickness, $d_{\mathrm{YSZ}}$

Cathode thickness, $d_{\mathrm{LSM}}$
Value

$50 \mu \mathrm{m}$

$2.5 \cdot 10^{12} \mathrm{~m} \cdot \mathrm{m}^{-2}$

$250 \mu \mathrm{m}$

$50 \mu \mathrm{m}$
Reference

5
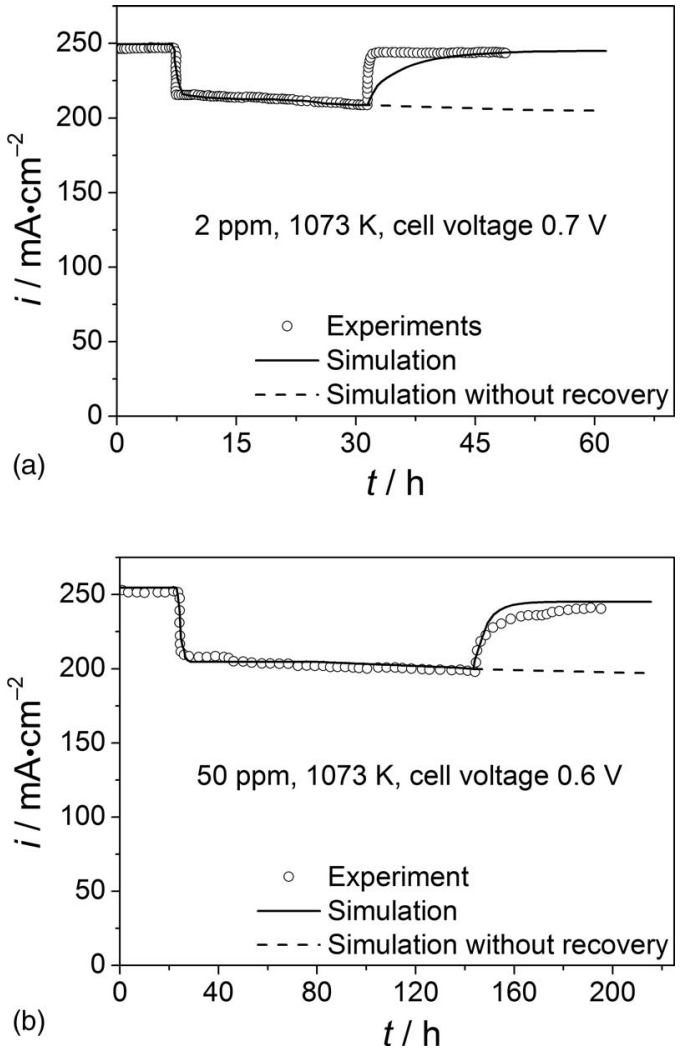

Figure 6. Simulated and experimental data for sulfur poisoning and regeneration processes of Ni-YSZ anodes in a fuel mixture with (a) $2 \mathrm{ppm}(E=0.7$ V) and (b) $50 \mathrm{ppm} \mathrm{H}_{2} \mathrm{~S}(E=0.6 \mathrm{~V})$. 


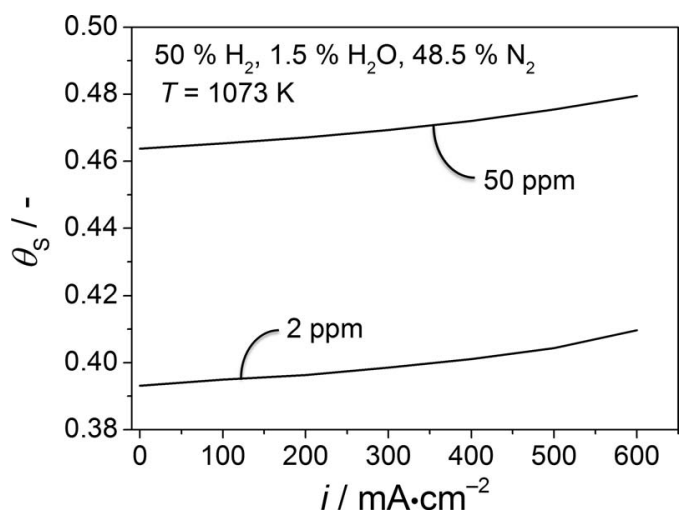

Figure 7. The change of sulfur coverage with cell current density for $\mathrm{H}_{2} \mathrm{~S}$ gas phase concentrations of $2 \mathrm{ppm}$ and $50 \mathrm{ppm}$ corresponding to results shown in Fig. 6(ab).

exponential function was included in Eq. 8. Also, it shall be noted that the $2^{\text {nd }}$ stage degradation should be modeled by either secondary phase formation or anode microstructural changes, which leads to a decrease of TPB length. However, due to unsufficient knowledge about the origin of the latter processes and the corresponding kinetic and thermodynamic data, a gradual reduction of TPB length was employed. Certainly, this phenomenon has significant influence on cell performance and it will be a purpose of our future work.

For deeper insights into the mechanistic details of sulfur poisoning, the calculated equilibrium sulfur coverage on the Ni surface as a function of current density is shown in Figure 7. It should be noted that the respective calculations were carried out without the inclusion of Eq. 8, i.e. they reflect the physicochemical behavior after completion of the initial performance drop.

It can be seen that at a $\mathrm{H}_{2} \mathrm{~S}$ gas phase concentration of $50 \mathrm{ppm}$ a considerably higher sulfur surface coverage is achieved than at 2 ppm. This can be assumed to be the reason for the higher current density drop at the $50 \mathrm{ppm}$ system. The sulfur coverage for both $2 \mathrm{ppm}$ and $50 \mathrm{ppm} \mathrm{H}_{2} \mathrm{~S}$ increase non-linearly with current density. The reason for this increase is likely to be the increase of the charge transfer reaction rate that results in a higher oxygen ion flux and thus, a higher hydrogen oxidation rate and hydrogen removal from the surface via water desorption. The calculated coverages of all other species adsorbed on the Ni surface remain below $0.01 \mathrm{ML}$, i.e. they are not very stable. Therefore, more active surface sites become available for sulfur formation at higher current density. This is an interesting finding, since it is contrary to most previous studies, which suggest the increase of the sulfur removal rate via electrochemical oxidation caused by the larger oxygen ion flux induced by high current densities. , $6,13,14,50^{-1}$

A possible explanation for this behavior was recently indicated by Cheng et al. ${ }^{15}$ In their study, the authors have used simple correlations based on the Tafel equation to show that the decreasing relative total anode resistance with current density is the inherent Tafel behavior and thus, is not related to the decreasing sulfur coverage on the $\mathrm{Ni}$ surface.

As shown in Fig. 5, in the present work we quantitatively reproduced the decreasing relative total anode resistance with current density. The fact that this behavior is accompanied by a simultaneous increase in sulfur coverage, as illustrated in Fig. 7, qualitatively verifies the mechanism described by Cheng et al. ${ }^{15}$

Modeling of electrolyte-supported SOFC performance: Galvanostatic versus potentiostatic regime.- As it was briefly described above the relative power output drop caused by sulfur poisoning decreases as the cell voltage is lowered potentiostatically, however, it increases with higher current density in the galvanostatic mode. In order to verify these phenomena we have performed potentiostatic and galvanostatic relative power drop calculations. Therefore, we use experimental results of Cheng et al., who have investigated LSM-based electrolyte-

\begin{tabular}{lcc}
\hline $\begin{array}{l}\text { Table VI. Model parameters used to reproduce the experimental } \\
\text { results from Cheng et al. }\end{array}$ & \\
Parameter & Value & Reference \\
\hline Anode thickness, $d_{\mathrm{Ni} / \mathrm{YSZ}}$ & $50 \mu \mathrm{m}$ & 9 \\
Anode TPB length & $6.3 \cdot 10^{12} \mathrm{~m} \cdot \mathrm{m}^{-2}$ & Fit \\
Electrolyte thickness, $d_{\mathrm{YSZ}}$ & $250 \mu \mathrm{m}$ & 9 \\
Cathode thickness, $d_{\mathrm{LSM}}$ & $50 \mu \mathrm{m}$ & 9
\end{tabular}

supported cells in a fuel mixture of $50 \% \mathrm{H}_{2} / 1.5 \% \mathrm{H}_{2} \mathrm{O} / 48.5 \% \mathrm{~N}_{2}$ and various trace amounts of $\mathrm{H}_{2} \mathrm{~S}$ under both galvanostatic and potentiostatic conditions at $1073 \mathrm{~K}$.

Using the kinetic parameters developed and validated above and the cell-specific parameters listed in Table VI, Figure 8 shows the comparison between the model predictions and experimental data by Cheng et al. ${ }^{6}$

In Figure 8a, a comparison between the experimental and simulated values of the relative voltage drops for different $\mathrm{H}_{2} \mathrm{~S}$ concentrations under galvanostatic conditions is shown. Figure $8 \mathrm{~b}$ shows the relative current density drops under potentiostatic conditions.

In galvanostatic mode, the authors measured the relative voltage drops at constant current densities of $i=241 \mathrm{~mA} \cdot \mathrm{cm}^{-2}$ and $i=409$ $\mathrm{mA} \cdot \mathrm{cm}^{-2}$, corresponding to initial cell voltages of $0.708 \mathrm{~V}$ and 0.534 $\mathrm{V}$, respectively. They observed that the relative voltage drop curve was greater at higher current density for all tested $\mathrm{H}_{2} \mathrm{~S}$ concentrations.

At potentiostatic mode, the relative current density drops were determined at the voltages $E=0.7 \mathrm{~V}$ and $E=0.535 \mathrm{~V}$ (corresponding to initial current densities of $260 \mathrm{~mA} \cdot \mathrm{cm}^{-2}$ and $432 \mathrm{~mA} \cdot \mathrm{cm}^{-2}$ )
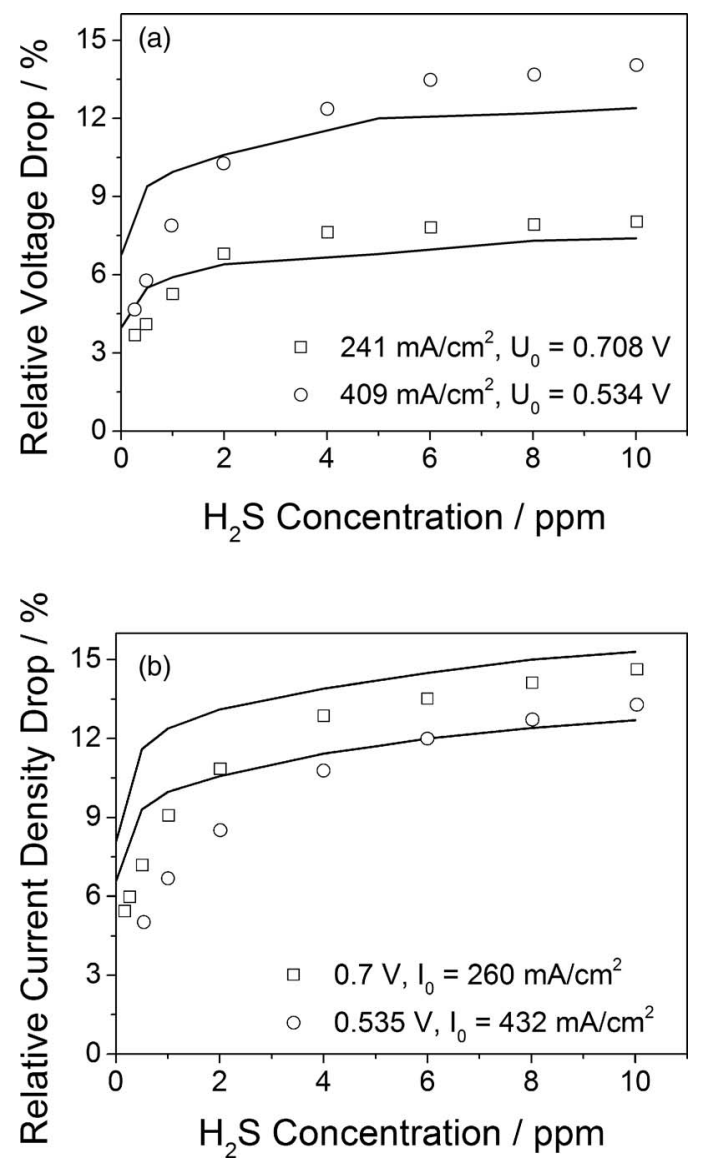

Figure 8. Comparison between the experimental and simulated values for the relative voltage drop (a) and current density drop (b) for different conditions at $T=1073 \mathrm{~K}$ 
consistent with the initial cell voltages from the galvanostatic measurements. In contrast to the results obtained for constant cell current densities, the relative current density drop was greater for the cell voltage of $0.7 \mathrm{~V}$, that is, for the lower initial cell current density.

There are two distinguished regions in the relative power output drop shown in Fig. 8. At the beginning, the degree of poisoning is drastically increasing with increasing $\mathrm{H}_{2} \mathrm{~S}$ concentrations (up to about 4 $\mathrm{ppm}$ ), which is followed by almost constant performance drops at higher concentrations. As illustrated in Fig. 8, the behavior of experimental measurements can be represented well by our model for a variety of $\mathrm{H}_{2} \mathrm{~S}$ concentrations. There is a substantial discrepancy between simulated and experimental results for the relative current density drop at small $\mathrm{H}_{2} \mathrm{~S}$ concentration, however, we have already demonstrated, in the previous section, the validity of our model for a $\mathrm{H}_{2} \mathrm{~S}$ concentration of $2 \mathrm{ppm}$ at $0.7 \mathrm{~V}$ under potentiostatic mode. Thus, the observed deviation for the relative current density drop might be related to limited information about structure and geometry of the experimental cell taken from literature. However, the existence of an important physical process that is not represented by our model and influences the relative current density drop at small $\mathrm{H}_{2} \mathrm{~S}$ concentrations cannot be excluded. Nevertheless, the overall simulation results show that the developed sulfur poisoning model provides a reasonable representation of the galvanostatic and potentiostatic behavior, especially at relatively high $\mathrm{H}_{2} \mathrm{~S}$ concentrations that are observed more often in practical SOFC operation.

Sensitivity analyses. - The simulation results shown above have demonstrated the validity of our model for a wide range of operating conditions. In order to further investigate the sulfur poisoning behavior as a function of operational, geometrical and physicochemical parameters, sensitivity analyses were carried out. Sensitivity analysis is a tool used to quantitatively determine the dependencies of the macroscopic electrochemical behavior on model parameters. In the performed analyses the investigated parameters $P$ (geometrical, kinetic, thermodynamic, etc.) are varied separately by $5 \%$ and their effect on the investigated macroscopic quantity is quantified by the relative sensitivity $s$. In the present paper, the relative sensitivities of the total anode resistance $R_{\mathrm{p}}$ and sulfur coverage on $\mathrm{Ni}, \theta\left(\mathrm{S}_{\mathrm{Ni}}\right)$ are determined. The dimensionless relative sensitivity, in the example of the total anode resistance $R_{\mathrm{p}}$, is calculated as $s\left(R_{\mathrm{p}}\right)=\left(\Delta R_{\mathrm{p}} / R_{\mathrm{p}}\right) /(\Delta P / P)$. The same procedure is applied to test the effect of sulfur coverage change toward the change of physico-chemical parameters. In the following, a relative sensitivity of unity signifies a proportional impact of the parameter on the macroscopic quantity. Sensitivity values close to zero mean that the parameter has no influence on the quantity. Negative sensitivities represent a decrease of the investigated quantity. The sensitivity of all parameters used in the model was tested; in Fig. 9 and Fig. 10 only the results for parameters are reported that actually have a significant influence on the respective macroscopic quantity.

The sensitivity analysis toward the change of total anode resistance $\left(R_{\mathrm{p}}\right)$ shown in Figure 9 has been performed based upon impedance spectra from Figure 5. As it is indicated in Fig. 9, for $R_{\mathrm{p}}$, a sensitivity analysis was carried out at two different temperatures ( $923 \mathrm{~K}$ and $1023 \mathrm{~K})$. The results are divided into four different categories. These are (i) thermodynamic and kinetic parameters, $(i i)$ the electrochemical double layer capacitance, (iii) geometrical parameters of the cell and (iv) physical parameters (in our model this is only pressure). The strong sensitivity of $\theta\left(\mathrm{S}_{\mathrm{Ni}}\right)$ toward the enthalpy and entropy of sulfur demonstrates the difficulties associated with the modeling of sulfur poisoning. Already small deviations from the real thermodynamic data of sulfur lead to a strong divergence between experiments and simulation results. The analysis also reveals that the charge-transfer reaction $\mathrm{C} 1$ has significant influence on total anode resistance for both temperatures. Another co-limiting reaction is the $\mathrm{H}_{2} \mathrm{O}$ adsorption on YSZ that is involved in providing the reactants for the charge-transfer reaction. Moreover, $R_{\mathrm{p}}$ is sensitive toward the enthalpies of $\mathrm{O}_{\mathrm{YSZ}}^{2-}$ and $\mathrm{H}_{2} \mathrm{O}_{\text {YSZ }}$, both involved in the rate co-limiting reactions. Furthermore, $R_{\mathrm{p}}$ is sensitive to the change of several geometrical parameters, the $\mathrm{Ni} / Y S Z$ interfacial double layer and pressure.

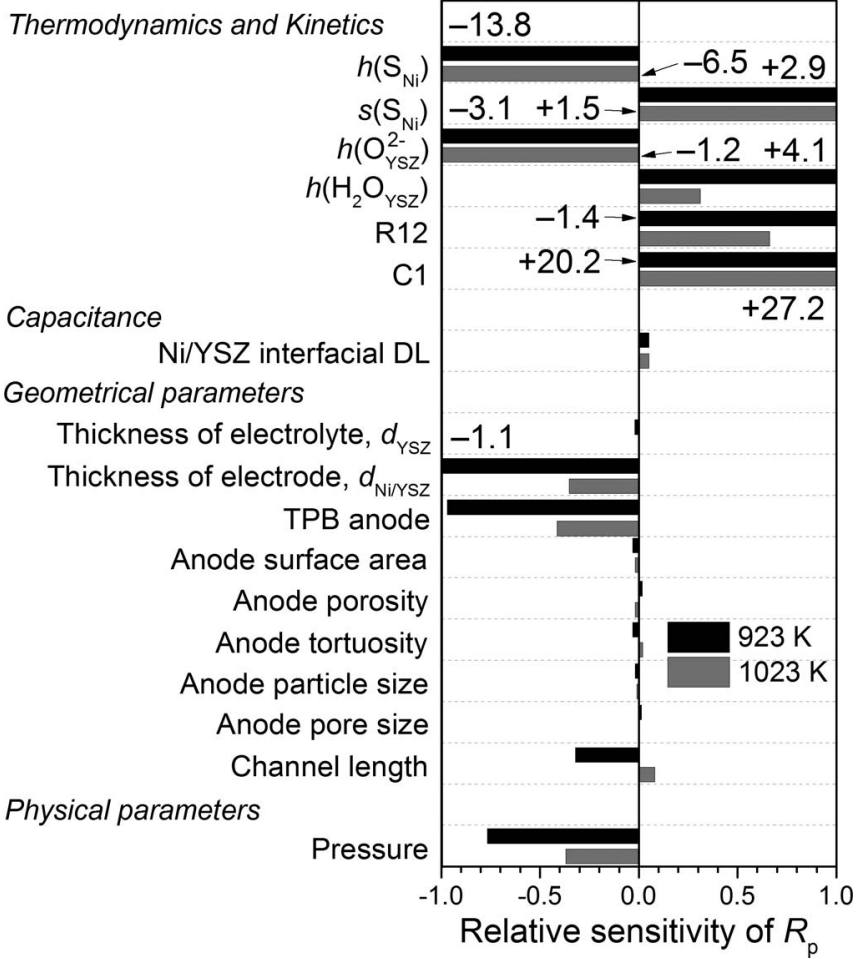

Figure 9. Sensitivity analysis of the total anode resistance $\left(R_{\mathrm{p}}\right)$ at two different temperatures. For further details see text.

Many of these parameters have also shown to have a significant effect on $R_{\mathrm{p}}$ for systems without $\mathrm{H}_{2} \mathrm{~S} .{ }^{35}$ Hence, we performed another sensitivity analysis toward $\theta\left(\mathrm{S}_{\mathrm{Ni}}\right)$, since sulfur coverage was identified to be the key parameter dictating the performance loss in sulfur-containing systems. The sensitivity analyses toward the change of sulfur coverage were performed at two different cell voltages $(0.7 \mathrm{~V}$ and $0.3 \mathrm{~V}$ ) and temperature of $1023 \mathrm{~K}$. Again, the results are divided into two categories, namely thermodynamic and kinetic parameters. As expected, $\theta\left(\mathrm{S}_{\mathrm{Ni}}\right)$ is very sensitive toward the enthalpy and entropy of sulfur. This sensitivity is decreasing for lower cell voltages (i.e. higher current densities). However, as already noted above this behavior is not due to increasing sulfur removal, but rather caused by the enhanced charge transfer reaction rate, that results in the increase of water formation rate and thus, reduced competitive adsorption of sulfur with hydrogen. $\theta\left(\mathrm{S}_{\mathrm{Ni}}\right)$ also shows a significant sensitivity toward the thermodynamic data of adsorbed hydrogen atom on Ni surface. The strong coverage dependency of sulfur and its high surface coverage illustrate that its presence on the surface highly affects the surrounding adsorbates. Thus, the introduction of a coverage dependency for $h\left(\mathrm{H}_{\mathrm{Ni}}\right)$ and/or $s\left(\mathrm{H}_{\mathrm{Ni}}\right)$ might lead to an improvement of the simulation results. Although, as it is discussed above, there is evidence in literature, ${ }^{20}$ which suggests the coverage-dependent modification of the hydrogen atom enthalpy on $\mathrm{Ni}$ surface, we have decided to keep this value constant in order to decrease the number of fitting parameters. However, if further experimental and theoretical thermodynamic data concerning the coverage dependency of the hydrogen atom enthalpy and/or entropy becomes available, the refinement of their values might be valuable.

Considering the influence of the physico-chemical processes on sulfur coverage, the performed sensitivity analysis shows that the charge transfer reaction $\mathrm{C} 1$ and reaction $\mathrm{R} 13$ which is delivering the reactants for $\mathrm{C} 1$ are the rate co-limiting steps. Correspondingly, the thermodynamic data of species involved in these reactions also have a high influence on coverage. All other reactions are fast and not co-limiting. Thus, their rate coefficients only have a minor influence on sulfur coverage. Neither the kinetics of the reactions leading to 


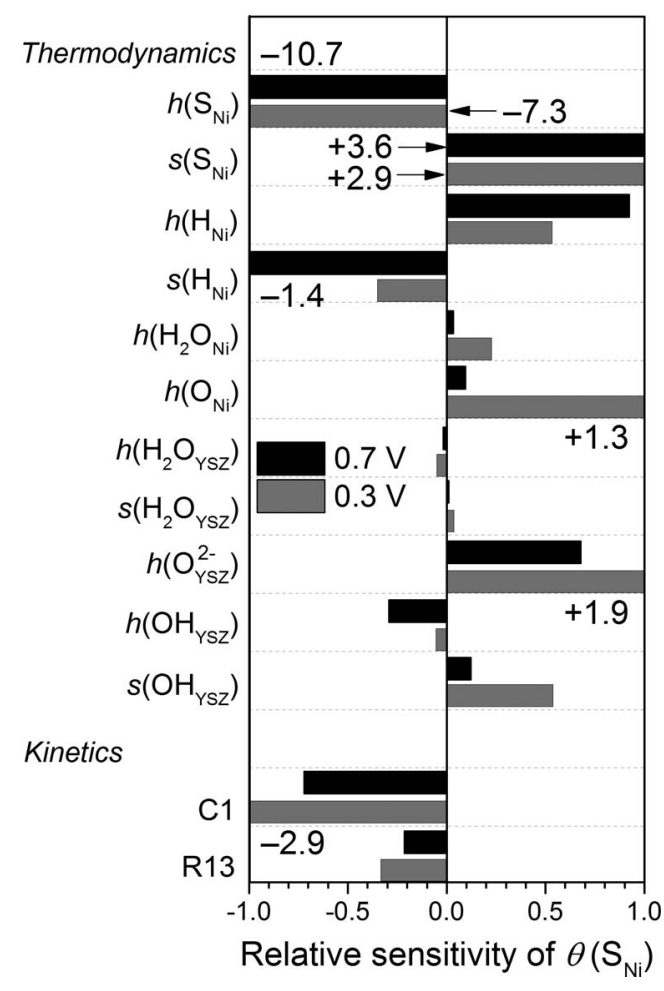

Figure 10. Sensitivity analysis of the sulfur coverage $\theta\left(\mathrm{S}_{\mathrm{Ni}}\right)$ at two different cell voltages. For further details see text.

sulfur oxidation to $\mathrm{SO}_{2}$ nor the thermodynamic data of the involved species have any impact on sulfur coverage. Thus, their accuracy has no significant impact on the simulation outcome.

Figure 10 shows that the coverage of sulfur is sensitive toward more thermodynamic parameters than kinetic parameters. Thus, as $\theta\left(\mathrm{S}_{\mathrm{Ni}}\right)$ can be regarded to be the key parameter describing sulfur poisoning, it can be stated that sulfur poisoning is driven thermodynamically.

\section{Conclusions}

We have presented an elementary kinetic model of SOFC Ni/YSZ anode degradation caused by sulfur poisoning. A detailed multi-step reaction mechanism of sulfur formation and oxidation was developed for SOFC operation with trace amounts of hydrogen sulfide. The derived chemical model was validated against literature-based sulfur chemisorption isobars, and subsequently was used to analyse performance drops of anode- and electrolyte-supported SOFC working under typical fuel cell operating conditions. Literature taken impedance spectra, current density and voltage stability tests were successfully reproduced for different $\mathrm{H}_{2} \mathrm{~S}$ gas phase concentrations and temperatures.

In the present work we have used the elementary kinetic approach which significantly depends on thermodynamic consistency and microscopic reversibility of all reactions. Therefore, it requires quantitative thermodynamic data for all species involved in the reactions. An important contribution of this work is the compilation of a complete set of thermodynamic data for the relevant species and kinetic parameters for corresponding heterogeneous reactions from various literature sources.

In contrast to the widely spread assumption that an increasing current density leads to electrochemical oxidation of sulfur and thus, reduced sulfur surface coverage, we have shown that the coverage is actually increasing, despite decreasing total anode resistance. As already recently speculated, the results of our simulations qualitatively confirm the hypothesis that decreasing cell total anode resistance with current density is the inherent Tafel behavior and, thus, cannot be explained by the sulfur coverage.

The thermodynamic and kinetic data set developed in the present work will form the basis for future investigations of more complex SOFC fuels, as for example syngas or hydrocarbons.

\section{Acknowledgments}

V. Yurkiv acknowledges funding by the Initiative and Networking Fund of the Helmholtz Association. Prof. Wolfgang G. Bessler (Offenburg University of Applied Science, Offenburg, Germany) is gratefully acknowledged for sharing his experience in the development of the model presented in this work. We gratefully acknowledge financial support by the German Ministry of Education and Research via grant number 03SF0494C.

\section{References}

1. S. C. Singhal and K. Kendall, High Temperature Solid Oxide Fuel Cells: Fundamental, Design and Applications, p. 410, Elsevier Advanced Technology, Oxford, UK, (2003).

2. R. Kee and H. Zhu, Combust. Sci. Technol., 180, 1207 (2008).

3. B. V. R. S. N. Prasad and V. M. Janardhanan, J. Electrochem. Soc., 161, F208 (2013).

4. K. Sasaki, K. Susuki, A. Iyoshi, M. Uchimura, N. Imamura, H. Kusaba, Y. Teraoka, H. Fuchino, K. Tsujimoto, Y. Uchida, and N. Jingo, J. Electrochem. Soc., 153, A2023 (2006).

5. S. Zha, Z. Cheng, and M. Liu, J. Electrochem. Soc., 154, B201 (2007).

6. Z. Cheng, S. Zha, and M. Liu, J. Power Sources, 172, 688 (2007).

7. Y. Matsuzaki and I. Yasuda, Solid State Ionics, 132, 261 (2000).

8. A. Lussier, S. Sofie, J. Dvorak, and Y. Idzerda, Int. J. Hydrogen Energy, 33, 3945 (2008).

9. L. Yang, Z. Cheng, M. Liu, and L. Wilson, Energy Environ. Sci., 3, 1804 (2010).

10. J. F. B. Rasmussen and A. Hagen, J. Power Sources, 191, 534 (2009)

11. H. Kishimoto, T. Horita, K. Yamaji, M. E. Brito, Y.-P. Xiong, and H. Yokokawa, J. Electrochem. Soc., 157, B802 (2010).

12. J. Oudar, Catal. Rev. Eng., 22, 171 (1980).

13. E. Brightman, D. G. Ivey, D. J. L. Brett, and N. P. Brandon, J. Power Sources, 196, 7182 (2011).

14. E. Brightman, R. Maher, D. Ivey, G. Offer, and N. Brandon, ECS Trans., 35(1), 1407 (2011).

15. Z. Cheng, J.-H. Wang, Y. Choi, L. Yang, M. C. Lin, and M. Liu, Energy Environ. Sci., 4, 4380 (2011).

16. D. R. Alfonso, Surf. Sci., 602, 2758 (2008).

17. J.-H. Wang and M. Liu, Electrochem. commun., 9, 2212 (2007).

18. C.-H. Yeh and J.-J. Ho, Chemphyschem, 13, 3194 (2012).

19. N. Galea, J. Lo, and T. Ziegler, J. Catal., 263, 380 (2009).

20. D. Monder and K. Karan, ECS Trans., 57(1), 2449 (2013).

21. F. N. Cayan, S. R. Pakalapati, I. Celik, C. Xu, and J. Zondlo, Fuel Cells, 12, 464 (2012).

22. J. B. Hansen, Electrochem. Solid-State Lett., 11, B178 (2008).

23. I. Alstrup, J. Rostrup-Nielsen, and S. Røen, Appl. Catal., 1, 303 (1981).

24. D. J. L. Brett, A. Atkinson, N. P. Brandon, and S. J. Skinner, Chem. Soc. Rev, 37, 1568 (2008)

25. W. G. Bessler, S. Gewies, and M. Vogler, Electrochim. Acta, 53, 1782 (2007).

26. V. Yurkiv, R. Costa, Z. Ilhan, A. Ansar, and W. G. Bessler, J. Electrochem. Soc., 161, F480 (2014).

27. J. Neidhardt and D. Fronczek, J. Electrochem. Soc., 159, A1528 (2012)

28. S. B. Adler and W. G. Bessler, in Handbook of Fuel Cells: Fundamentals, Technology and Applications, Vol. 5, A. L. W. Vielstich, H. A. Gasteiger, and H. Yokokawa, Editors, p. 441, John Wiley \& Sons Ltd., Chichester (2009).

29. W. G. Bessler, J. Electrochem. Soc., 153, A1492 (2006).

30. P. Deuflhard, E. Hairer, and J. Zugck, Numer. Math., 51, 501 (1987).

31. W. G. Bessler, Solid State Ionics, 176, 997 (2005).

32. V. Yurkiv, A. Utz, A. Weber, E. Ivers-Tiffée, H.-R. Volpp, and W. G. Bessler, Electrochim. Acta, 59, 573 (2012)

33. D. G. Goodwin, H. Zhu, A. M. Colclasure, and R. J. Kee, J. Electrochem. Soc., 156 B1004 (2009).

34. C. Bao and X. Zhang, Electrochim. Acta, 130, 785 (2014).

35. M. Vogler, A. Bieberle-Hütter, L. Gauckler, J. Warnatz, and W. G. Bessler, J. Electrochem. Soc., 156, B663 (2009).

36. W. G. Bessler, M. Vogler, H. Störmer, D. Gerthsen, A. Utz, A. Weber, and E. Ivers-Tiffée, Phys. Chem. Chem. Phys., 12, 13888 (2010).

37. M. W. Chase Jr., J. Phys. Chem. Ref. Data, Monograph 9, 1 (1998).

38. J. G. McCarty and H. Wise, J. Chem. Phys., 72, 6332 (1980).

39. C. H. Bartholomew, P. K. Agrawal, and J. R. Kratzer, Adv. Catal., 31, 135 (1982).

40. S. Appari, V. M. Janardhanan, R. Bauri, S. Jayanti, and O. Deutschmann, Appl. Catal. A Gen., 471, 118 (2014).

41. E. S. Hecht, G. K. Gupta, H. Zhu, A. M. Dean, R. J. Kee, L. Maier, and O. Deutschmann, Appl. Catal. A Gen., 295, 40 (2005).

42. V. Yurkiv, D. Starukhin, H.-R. Volpp, and W. G. Bessler, J. Electrochem. Soc., 158, B5 (2011). 
43. R. B. Getman and W. F. Schneider, ChemCatChem, 2, 1450 (2010),

44. L. C. Grabow, B. Hvolbæk, and J. K. Nørskov, Top. Catal., 53, 298 (2010).

45. S. D. Miller and J. R. Kitchin, Surf. Sci., 603, 794 (2009).

46. A. B. Mhadeshwar, J. R. Kitchin, M. A. Barteau, and D. G. Vlachos, Catal. Letters, 96, 13 (2004).

47. C. H. Bartholomew, Appl. Catal. A Gen., 212, 17 (2001).
48. H. Zhu, A. Kromp, A. Leonide, E. Ivers-Tiffee, O. Deutschmann, and R. J. Kee, $J$. Electrochem. Soc., 159, F255 (2012).

49. M. B. Mogensen, X. Sun, S. Koch, C. Graves, K. Vels, and K. Hansen, Proc. EFCF 2014, B1209 (2014)

50. J. R. Rostrup-Nielsen, J. B. Hansen, S. Helveg, N. Christiansen, and A. K. Jannasch, Appl. Phys. A, 85, 427 (2006) 